\title{
PENGETAHUAN LOKAL DALAM EPISTEMOLOGI RELASIONAL: KAJIAN FILSAFAT KEBUDAYAAN
}

\author{
I Gede Mudana \\ Jurusan Pedalangan, Fakultas Seni Pertunjukan, \\ Institut Seni Indonesia Denpasar, Indonesia
}

\begin{abstract}
: local knowledge or invented tradition has to be related ("suturing") to the globalization occurring these days. As a traditional capital, it has to be supported in the field of cultural studies. Using an example of tri hita karana in Bali, with its natural-human-religious relations, such knowledge is none other than a new paradigm called relational epistemology. A postmodern cultural studies, through the epistemology and its binary-opposition way, tries to ignore every opposition and contradiction in the modern life (modernity).
\end{abstract}

Key words: Local knowledge, cultural studies and relational.

Membicarakan secara epistemologis eksistensi kearifan lokal dalam era globalisasi masa kini setidaknya, dalam pemahaman penulis, adalah membicarakan pengetahuan lokal dalam konteks kajian budaya di samping dalam konteks epistemologi relasional yang ingin dibahas dalam tulisan ini. Dikatakan demikian karena membicarakan (ke)ilmu(an) masa kini, salah satu yang paling populer dan menjadi kecenderungan, di antaranya, adalah membicarakan kajian budaya (cultural studies) betapapun pokok masalah yang dibicarakan adalah diskursus-diskursus yang lekat dengan nuansa kemasalaluan, seperti kearifan lokal (local wisdom) di sini penulis lebih suka menggunakan istilah "pengetahuan lokal" (local knowledge).

Kajian budaya memang "disiplin ilmu" yang senantiasa menyambungkan (suturing, istilah yang kerap dikemukakan oleh Prof. Dr. I Gusti Ngurah Bagus (almarhum) kemasalaluan dengan kepentingannya di masa kini untuk emansipasi manusia si pencipta/pemilik/pelaksana/pemakai disiplin ilmu tersebut. Itulah sebabnya mengapa eksistensi kearifan lokal dalam era globalisasi serta merta di sini dicoba di-suturing dengan pengetahuan lokal dalam konteks kajian budaya. Karenanya, dengan segala kerendahan hati, tulisan ini terutama menelisik secara agak filsafati khususnya filsafat kebudayaan pengetahuan lokal dalam epistemologi relasional sebagaimana yang dikemukakan dalam judul tulisan. 
Dari keberadaan kearifan lokal dalam era globalisasi, kesan luar yang pertama-tama muncul adalah semacam "contradictio in terminis", yakni sebuah pertentangan yang dibawa oleh tema itu sendiri. Kearifan/pengetahuan lokal, yang nota bene sebuah proses pemberdayaan lokalitas-lokalitas "dilawankan" dengan gerakan-gerakan maha dasyat dan serba besar bernama globalisasi.

Globalisasi bukanlah "gombalisasi". Ia merupakan fenomena yang benar-benar ada: bukan citra, bukan sekadar rekaan, apalagi guyonan iseng. Banyak yang mencoba mendefinisikan dan mengidentifikasinya tetapi, secara umum, ia tetap fenomena pergerakan bebas kehidupan manusia dan kebudayaannya. Dengan dibantu oleh teknologi, termasuk dan terutama teknologi informasi dan transportasi, manusia bisa bergerak dan pergi ke mana saja tanpa batas (borderless). Bahkan lebih dari itu, Arjun Appadurai (1990:295-310.) menandainya sebagai suatu hubungan di antara lima dimensi: a) ethnoscape, b) mediascape, c) technoscape, d) finanscape, dan e) ideoscape.

Tentang hubungan antara globalisasi dan lokalisasi, ia sebenarnya bukan sekadar sebuah pertentangan biasa, tetapi yang terjadi adalah sebuah proses dialektik. Dalam pendekatan dialektika, yang secara umum dapat dikatakan diwarisi dari Karl Marx dan bahkan dari Hegel, sebuah tesis akan dihadapi oleh sebuah antitesis yang kemudian menghasilkan sebuah sintesis. Dengan itu, globalisasi adalah tesis, lokalisasi adalah antitesis, maka sintesis keduanya adalah apa yang dapat disebut "glokalisasi" dari kata globalisasi dan lokalisasi. Istilah glocal (globalism dan localism) diperkenalkan oleh Mike Featherstone dalam karyanya Undoing Culture, Globalization, Postmodernism, and Identity (1995) yang tampak jelas dalam contoh budaya populer musik pop Bali (lihat: Darma Putra, 2004:89-108.).

Ini berarti, yang sesungguhnya terjadi tidak saja globalisasi secara linear tetapi juga glokalisasi. Pada saat dunia berubah menjadi "the global village", sebuah konsep Marshall McLuhan yang ditulis dalam sejumlah bukunya, di antaranya War and Peace in the Global Village (1968), atau menjadi satu dunia (yang "sama"), ia juga pergi menuju fragmentasi, keterpecah-pecahan, sebuah proses lokalisasi. Di Bali misalnya, dalam contoh besarnya, globalisasi diselang-selingi oleh bergerak majunya lokalitas-lokalitas, termasuk di antaranya dengan mengemukanya ideologi "ajeg Bali" di sejumlah media massa lokal yang sangat membius dan memabukkan begitu banyak manusia Bali kontemporer.

Fenomena gaya hidup mengglobal, misalnya budaya massa sepakbola atau potongan rambut mendunia gaya Demi More, boleh ke mana-mana dan ke sini tetapi, pada saat yang sama, senantiasa terdapat gerakan-gerakan sosial, adat, dan agama yang sebaliknya, di antaranya di sini membentuk semangat mencari lelintihan, leluhur, soroh, kewangsan, dan simbol-simbol primordial lainnya. Anak-anak muda yang pergi bersembahyang ke pura pun 
melakukannya sembari memanjakan nafsu fetisisme citarasa terkini: berdandan funky layaknya bule-bule di tempat wisata Kuta, bercengkerama begitu gaul dengan "lu-lu-gue-gue", atau ber-HP-ria sambil ditemani: ... Coca Cola (tentu!).

Namun demikian, penulis tidak berpretensi bisa menjawab keseluruhan permasalahan yang luas dan kompleks dari persambungan pengetahuan lokal dan globalisasi ke dalam epistemologi kajian budaya, yakni suatu wilayah yang sampai saat ini sesungguhnya belum sangat banyak dikenal secara benar di negeri ini dan bahkan sering disalahpahami kalau bukan "dizalimi". Di samping itu, membedah kepentingan pengetahuan lokal di masa kini adalah mengurai "teka-teki" posmodernisme, sesuatu yang juga, seperti kajian budaya, sering kurang dimengerti secara memadai (Lebih ekstrem lagi, posmodernisme sering dianggap aneh, sok, suka meng-ada-ada, dan nihilisme, sehingga tidak jarang dirasakan perlu dienyahkan dari kancah lalu lintas intelektualitas). Padahal, perbincangan glokalisasi $(=$ globalisasi + lokalisasi $)$ tidak lain adalah perbincangan posmodernisme.

\section{KEGAYUTAN PENGETAHUAN LOKAL}

Karena kita bersepakat dengan permasalahan pengetahuan dalam "konteks kajian budaya" dengan epistemologi relasionalnya, maka kajian budaya pantas untuk sedikit diuraikan meskipun dalam sebuah hamparan sekilas, sebelum benar-benar pergi ke permasalahan yang lebih substansial.

Asal usul kata "cultural studies" berasal dari Centre for Contemporary Cultural Studies (CCCS), yang berdiri pada tahun 1964 di University of Birmingham, Inggris. Penerbitan pertama Centre for Contemporary Cultural Studies adalah Working Pappers in Cultural Studies pada tahun 1972 yang memiliki tujuan "mendefinisikan dan mengisi ruang" dan "menempatkan cultural studies di peta intelektual". Sejak itu, karya-karya yang dibuat di Centre for Contemporary Cultural Studies mendapatkan status yang melegenda di bidang cultural studies. Dalam hal ini, karya-karya Richard Hoggart, Raymond Williams, E.P. Thompson, Stuart Hall, yang diasosiasikan dengan Centre for Contemporary Cultural Studies di berbagai kesempatan dianggap teks-teks dasar cultural studies (Sardar dan Van Loon, 1997:24).

Dalam wacana kajian budaya, "kebudayaan" atau "budaya" harus dilihat dalam arti luas. Di Indonesia, termasuk di Bali, cukup banyak pihak yang selama ini justru berpandangan secara sempit bahwa hal itu hanya berhubungan dengan seni dan budaya atau kesenian dan estetika, seperti taritarian, produk lukisan, atau karya patung yang indah. Sebaliknya, 
sebagaimana dikatakan oleh John Fiske (Storey, 2000), kebudayaan (culture) dalam kajian budaya (cultural studies) tidak sekadar menekankan pada aspek estetik atau humanis melainkan juga aspek politik.

Salah satu definisi kebudayaan yang paling populer saat ini dan terutama yang sering digunakan di lapangan kajian budaya adalah yang berasal dari Raymond Williams, yang merupakan salah seorang penggagas cultural studies. Menurut Williams, kebudayaan harus dilihat sebagai cara hidup tertentu bagi sekelompok orang tertentu pada suatu periode tertentu (Storey, 2000). Hal yang cukup mendasar yang bisa diperoleh dari pendapatnya adalah kenyataan bahwa ia secara implisit ingin menanamkan bahwa kebudayaan harus merupakan ungkapan "dari bawah" atau dari masyarakat pendukung dan pemilik kebudayaan itu sendiri dan bukan sesuatu yang diciptakan kepada atau untuk mereka. berikut:

Sardar dan Van Loon (1997:3) menunjukkan ciri-ciri kajian budaya

1) Kajian budaya bertujuan meneliti permasalahan pokoknya dari segi praktik-praktik budaya dan hubungannya dengan kekuasaan. Sasaran tepatnya adalah menunjukkan hubungan-hubungan kekuasaan dan meneliti bagaimana hubungan-hubungan tersebut mempengaruhi dan membentuk praktik-praktik budaya.

2) Kajian budaya tidak semata-mata merupakan kajian kebudayaan yang seolah-olah merupakan satu entitas manasuka dari konteks sosial dan politik. Tujuannya adalah untuk memahami kebudayaan dalam seluruh bentuk kompleksnya dan menganalisis konteks sosial dan politik di mana ia memanifestasikan dirinya.

3) Kebudayaan dalam kajian budaya selalu melaksanakan dua fungsi: baik objek kajian maupun lokasi kritisisme dan aksi politik.

4) Kajian budaya mencoba menunjukkan dan merekonsiliasikan pembagian pengetahuan, untuk mengatasi keterpisahan antara bentukbentuk tacit knowledge (yaitu, pengalaman intuitif yang didasarkan budaya-budaya lokal) dan objective knowledge (yang disebut pengetahuan universal). Ia mengasumsikan suatu identitas umum dan kepentingan umum antara peneliti dan yang diteliti, antara pengamat dan yang diamati.

5) Kajian budaya setia pada evaluasi moral masyarakat modern dan pada garis radikal aksi politik. Tradisi kajian budaya tidak merupakan tradisi ilmu pengetahuan yang bebas nilai tetapi tradisi yang setia pada rekonstruksi sosial dengan keterlibatan politik kritis. Jadi, kajian budaya bertujuan untuk memahami dan mengubah struktur dominasi di mana-mana, tetapi khususnya dalam masyarakat-masyarakat kapitalis industrial. 
Secara kajian budaya, kebudayaan harus dimaknai sebagai suatu konstruksi sosial dan bukan secara esensialis sehingga ia bersifat dinamis dan sama sekali tidak statis (Kleden, 2001). Untuk itu, kebudayaan harus diartikan sebagai sesuatu yang berubah secara terus-menerus, berproses, dan tidak statis sesuai perkembangan masyarakat yang membentuknya. Kebudayaan tidak merupakan sesuatu yang pasif atau sekadar warisan dari generasi ke generasi. Kalau kebudayaan hanya merupakan warisan, manusia yang mendukung dan memiliki kebudayaan tersebut makin lama akan makin jauh dari kebudayaannya karena pada dasarnya kebudayaan berkembang sejalan dengan perkembangan manusianya.

Program Studi Magister (S2) Kajian Budaya Universitas Udayana sejak 1996 yang kemudian disusul oleh Program Pendidikan Doktor (S3) Kajian Budaya Universitas Udayana lima tahun setelahnya sampai saat ini tercatat sebagai lembaga pendidikan pascasarjana pertama di Indonesia yang secara eksplisit menggunakan nama "kajian budaya" dan bahkan memiliki paradigmanya yang disebut "paradigma budaya" yang diungkapkan ke dalam bentuk, fungsi, dan makna (Suastika, 2003) di mana hal tersebut dapat dikatakan merupakan ciri kemunculan "cultural studies mazhab Bali" yang digagas dan dipimpin oleh Prof. Dr. I Gusti Ngurah Bagus (Fadlillah, 2003a:18, 2003b:20-28).

Dari penjelasan di atas dapat dikatakan bahwa cultural studies di Inggris menjadi kajian budaya di Indonesia lewat Program S2 dan S3 Kajian Budaya Unud. Namun demikian, kajian budaya di S2 dan S3 Kajian Budaya Unud telah memodifikasi cultural studies sedemikian rupa yang disesuaikan dengan situasi dan kondisi yang ada, sehingga kajian budaya tetap kontekstual dan tidak bebas-nilai. Jadi, dihubungkan dengan karakteristik di atas, pertanyaannya adalah, di manakah letak kegayutan pengetahuan lokal.

\section{EPISTEMOLOGI RELASIONAL: DARI MODERN KE POSTMODERN}

Berbagai krisis dalam masyarakat dewasa ini (angka inflasi yang tinggi dan pengangguran, krisis energi, krisis penanganan kesehatan, polusi dan kerusakan lingkungan, maraknya kejahatan dan kriminalitas, dan masih banyak yang lainnya (semuanya tergolong krisis persepsi), seperti halnya krisis yang terjadi dalam fisika selama tahun 1920-an, muncul dari kenyataan penerapan konsep-konsep dari pandangan dunia yang telah usang pandangan dunia mekanistis sains Cartesian dan Newtonian. Sekarang kita (manusia) hidup dalam dunia yang saling berhubungan secara global, di mana fenomena-fenomena biologis, fisik, sosial, maupun lingkungan saling berketergantungan. Untuk menjelaskan dunia ini secara memadai kita memerlukan sebuah perspektif ekologis, yang tidak ditemukan dalam pandangan dunia Cartesian (Capra, 1997:xx). 
Dengan paradigma baru, yaitu pandangan holistik, ekologis, dan sistemik yang terinspirasi dari berlalunya kontekstualisasi fisika modern dari Newton, inti dari wacana mengenai revolusi dalam paradigma ilmu pengetahuan sebagaimana digambarkan oleh Capra sebenarnya hanya menginginkan keteguhan manusia untuk memegang keseimbangan dalam berhubungan dengan berbagai entitas lain dalam kehidupan di alam semesta ini. Dengan begitu, manusia tidak lagi bersifat antroposentrik tetapi menghormati berbagai unsur lainnya, yang sangat banyak. Manusia hanyalah salah satu unsur dan tidak berhak mendominasi atau menguasai berbagai unsur lainnya yang ada (Bagus, 2003).

Pandangan yang mengutamakan keseimbangan seperti itu bukannya tidak ada dalam masyarakat dan kebudayaan lokal, khususnya di Bali. Di sini, di antaranya, telah dikenal adanya tri hita karana, atau THK, yakni sebuah pengetahuan lokal yang karena kepopulerannya selalu disebut-sebut, dalam berbagai kesempatan dan dalam berbagai media, sebagai ikon utama kebudayaan setempat. Dikatakan demikian karena tri hita karana yang ditemukan oleh agamawan-budayawan I Gusti Ketut Kaler beberapa dasawarsa yang lalu ini sudah jelas mengondisikan harmoni antara manusia dengan Tuhan Sang Pencipta, dengan manusia lainnya, dan dengan alam lingkungan. Tanpa adanya kosmologi yang mengandung harmoni-harmoni, tidak akan ada kesejahteraan (hita) bagi manusia (Bagus, 2003). Parahyangan, pawongan, palemahan, di sini bisa saja dijajarkan dengan konsep-konsep teologis, sosiologis, ekologis, ataupun dengan ideofacts, sociofacts, artefacts. Menurut Kaler (1983), lewat tri hita karana, Tuhan dalam konsep teologi Hindu berproses secara imanen dan transenden (wyapiwyapaka) sehingga memunculkan keseimbangan-keseimbangan.

Dengan begitu, menjadi makin jelas bahwa THK adalah sebuah pengetahuan lokal. Hanya, tidak banyak buku teoretis yang secara lugas membahas pengetahuan lokal, dalam arti yang sebenarnya. Salah satu buku rujukan -inilah teks- yang penulis kira tergamblang dari yang ada hanyalah The Invention of Tradition (1988) yang disunting oleh Eric Hobsbawm dan Terence Ranger. Kearifan/pengetahuan lokal di sini disebut "the invention of tradition" yang dapat diindonesiakan sebagai penemuan tradisi atau disingkat PT. Dalam artikel pembukanya, Hobsbawm (1988) menyepakati,

"Invented tradition" is taken to mean a set of practices, normally governed by overtly or tacitly accepted rules and of a ritual or symbolic nature, which seek to inculcate certain values and norms of behaviour by repetition, which automatically implies continuity with the past. In fact, where possible, they normally attempt to establish continuity with a suitable historic past.

Yang tampak kemudian adalah, kearifan lokal, pengetahuan lokal, indigenous knowledge, local genius, cerlang budaya, penemuan tradisi, atau 
apa pun namanya, adalah sebuah epistemologi relasional. Ia adalah epistemologi mengenai hubungan-hubungan. Dalam pendapatnya tadi, Hobsbawm menyatakan, "tradisi yang ditemukan" menunjukkan ketersambungan (keterhubungan) dengan masa lalu. Ini berarti, masa lalu tidak benar-benar ditinggalkan meskipun zaman sudah berangkat sangat progresif.

Epistemologi relasional adalah sebuah paradigma. Ia merupakan sebuah paradigma dalam sistem pemikiran, dalam pandangan dunia, dan filsafat. Untuk keperluan tulisan ini, ingin ditunjukkan bahwa epistemologi relasional merupakan pembongkaran paradigmatis modernitas ke posmodernitas. Karenanya, ia berada sangat dekat dengan pembicaraanpembicaraan posmodernisme meskipun tidak banyak disadari.

Modernitas adalah epistemologi yang mengatur bentuk-bentuk pandangan dunia dan sistem pemikiran. Pada saat yang sama bisa dikatakan bahwa sistem sosial dan kultural membentuk epistemologi. Bentuk-bentuk yang mengatur pandangan dunia juga tampak dalam bentuk ilmu pengetahuan (ilmu politik, ekonomi, sosiologi, dan sebagainya). Ia juga dapat tampak dalam bentuk-bentuk institusi sosial, kebijakan, teknologi, dan norma sosial (Shimogaki, 1993). Inti kecenderungan epistemologi modernitas, tidak lain, adalah "Barat modern" yang diperinci oleh Shimogaki sebagai: a) pemisahan antara bidang sakral dan bidang duniawi, b) kecenderungan ke arah reduksionisme, c) pemisahan antara subjektivitas dan objektivitas, d) terjadi antroposentrisme, dan e) terjadi progresivisme.

Posmodernisme, dengan demikian, adalah kecenderungan baru yang sedang berupaya mengatasi divisionisme, reduksionisme, dan Erosentrisme. Kecenderungan itu dapat dibuktikan ada dalam setiap disiplin. Dalam rangka posmodernisme inilah pembicaraan mengenai, misalnya, epistemologi relasional Gregory Bateson menjadi relevan, di samping Michael Foucault dengan teori relasi kekuasaannya.

Perlu diingat bahwa Bateson tidak dapat diklasifikasikan kepada para penganut paradigma disiplin yang konvensional atau "biasa-biasa saja". Karya-karya akademisnya adalah tentang antropologi, biologi, teori informasi, psikiatri, genetika, dan ekologi. Pada awalnya memang tidak ada hubungan antara disiplin-disiplin itu, tetapi pada basis disiplin itu ia membangun epistemologi relasional. Dalam Mind and Nature (1979:34), ia mengatakan begini: Sains tak pernah membuktikan apapun. Sains sekali waktu memperbaiki hipotesis-hipotesis, dan kadang-kadang malah merusak hipotesis-hipotesis itu...

Bateson tidak setuju pada reduksi sesuatu menjadi elemen-elemen atau karakter khas. Perhubungan di sini adalah posisi kita dalam masyarakat dan sejarah, hubungan keluarga, hubungan ekonomi dan politik, bahasa, kebudayaan, pengalaman pribadi, determinasi fisik, dan sebagainya. Dalam pandangannya yang radikal, informasi (misalnya) adalah perbedaan. Tidak 
mudah untuk mendefinisikan perbedaan karena, menurutnya (Bateson, 1979:109), perbedaan adalah wujud alami dari relasi yang tidak berdimensi ruang dan waktu.

Sebagai ahli informasi, Bateson menjelaskan ketidak-ada-jarakan antara materi dan pikiran (mind). Di sini kelihatan jelas bahwa ia sedang menantang pemikiran modern yang serba dan sok memisahkan dan mereduksi. Modernitas adalah pemisahan antara subjektivitas dan objektivitas. Untuk itu, secara sangat berani, Bateson (1979:38-39) berpendapat: tidak ada pengalaman objektif. Semua pengalaman adalah subjektif... Sangat sedikit orang dalam kultur Barat meragukan objektivitas atau imajinasi visual atas dunia luar. Peradaban kita dilandasi secara mendalam oleh ilusi ini.

Foucault dalam Power/Knowledge (1980) menyajikan epistemologi seperti itu melalui hubungan-hubungan antara pengetahuan dan kekuasaan. Ia berpendapat (1980:131): ...truth isn't outside power, or lacking in power... truth isn't the reward of free spirits... Truth is a thing of this world. Each society has its regime of truth: that is, the types of discourse which it accepts and makes function as true...

Menurut Foucault (1980:131-132), dalam masyarakat seperti (masyarakat) kita, "ekonomi politik" truth dikarakterisasikan oleh empat hal. Pertama, "truth" berpusat pada bentuk diskursus ilmiah dan institusi-institusi yang menghasilkannya. Kedua, ia merupakan subjek bagi dorongan ekonomi dan politik yang konstan. Ketiga, ia adalah objek, dalam bentuknya yang beragam. Keempat, ia dihasilkan dan ditransmisikan di bawah kendali aparat ekonomi dan politik tertentu. Terakhir, ia adalah isu dari keseluruhan debat politik dan konfrontasi sosial.

Bahkan pengetahuan tidak luput dari analisis Foucault. Dari analisis sejarah tentang sistem hukuman dan disiplin, ia menyatakan: lain kekuasaan, lain pengetahuan (Foucault, 1985:135). Pengetahuan diserap dalam kekuasaan dan superioritasnya dibongkar.

Sebagai contoh lain, relasi yin dan yang juga merupakan keseimbangan-keseimbangan. Harmoni yin dan yang tersebut dapat disejajarkan dengan bumi dan langit, bulan dan matahari, malam dan siang, musim dingin dan musim panas, kelembaban dan kekeringan, kesejukan dan kehangatan, bagian dalam dan bagian luar. Fritjof Capra (1997:26) menulis, dalam kebudayaan Cina, yin dan yang tidak pernah dihubungkan dengan nilai-nilai moral. Yang baik bukanlah yin dan bukan pula yang melainkan keseimbangan dinamis antara keduanya, demikian pula yang buruk dan yang mengganggu adalah ketidakseimbangan antara keduanya.

Sebenarnya masih ada pakar-pakar lainnya yang juga merekam jaringan ketiadabatasan yang dibawa oleh paradigma epistemologi relasional seperti yang dibawakan oleh Bateson dan Foucault. Misalnya, salah satunya, Mark Hobart dalam After Culture: Anthropology as Radical Metaphysical 
Critique (2000, buku ini diterbitkan oleh PSM Kajian Budaya Unud) yang "begitu Bali" secara keras menentang pemisahan klasik realisme dan idealisme. Menjadi pertanyaan baginya (2000:7), bagaimana mungkin pikiran (mind) mampu secara akurat merepresentasikan dunia (dalam realisme) ataupun memahami dirinya/pikiran itu sendiri (dalam idealisme). Menurutnya, dalam ilmu-ilmu kemanusiaan, pendapat bahwa terjadi hirarki "the knower over the known" di mana "reality transcends the knower" tidaklah menolong.

Di India, Jagidish Chandra Bose (1858-1937), yaitu seorang guru besar di Presidency College, Kalkuta, dengan keahlian fisikanya dan bekal teologi keagamaan (Hindu)-nya yang sangat kental, dengan eksperimen ilmiahnya mampu membuktikan prinsip kesatuan (unity) kedudukan dan sensitivitas kesadaran, baik dalam yang hidup maupun yang tidak hidup (lihat Bagus dalam "Revolusi Iptek dan Tugas Ilmuwan Hindu"). Menurut Bagus, hal ini cocok dengan pandangan Wedanta yang menyatakan bahwa Brahman meresap dan terdapat di mana-mana. Kesadaran yang bersumber pada Wedanta ini merupakan temuan Bose yang terbesar. Karyanya di antaranya "Response in the Living and Non Living", dan dengan itulah ia disebut acharya, pemikir rohani, sebagaimana pada Acharya Sangkara Acharya Madwa, Acharya Ramanuja.

\section{PENUTUP}

Pengetahuan lokal THK rupanya ada di posisi sangat bagus dalam wacana kajian budaya. Sebagaimana diungkapkan oleh Sardar dan van Loon (1997:3) di atas, bahwa "Kajian budaya mencoba menunjukkan dan merekonsiliasikan pembagian pengetahuan, untuk mengatasi keterpisahan antara bentuk-bentuk tacit knowledge (yaitu, pengalaman intuitif yang didasarkan budaya-budaya lokal) dan objective knowledge (yang disebut pengetahuan universal). Ia mengasumsikan suatu identitas umum dan kepentingan umum antara peneliti dan yang diteliti, antara pengamat dan yang diamati".

THK pada dasarnya adalah tacit knowledge karenanya sering hanya bersifat lisan, tampak ketinggalan, dan terpinggirkan dan senantiasa dikalahkan oleh kemodernan objective knowledge, yang dianggap besar, maju, ilmiah, dan harus diacu. Sebagai tanda tradisi, ia (telah) disingkirkan dalam modernisme pembangunan (lihat, misalnya, aneka konflik pengembangan pariwisata yang tanpa henti di pulau pariwisata (Bali) ini, yang ujung-ujungnya hanya menghegemoni rakyat pemilik modal sosialbudaya tetapi memanjakan pemilik modal uang) namun justru kemudian diuraikan ketersambungan (relasi)-nya dalam posmodernisme.

Sebaliknya, dari perspektif modernisme, THK pasti dapat dipertanyakan aras keilmiahannya. Namun, di sisi lain, harus disadari bahwa 
"epistemologi relasional" THK justru memiliki "kelebihan" melalui relasinya dengan sesuatu di luar nalar (dalam hal ini parahyangan/Tuhan). Ini pula yang harus ditunjukkan lewat posmodernisme melalui wacanawacana kajian budaya. Itulah tugas ilmuwan, pengkaji budaya, sebagai orang yang banyak berkecimpung di dunia posmo itu, untuk menjelaskan kepada dunia perihal "keilmiahan" dan keepistemologirelasionalan THK dan pengetahuan-pengetahuan lokal lainnya di peta intelektual. Inilah kesempatan sangat pas bagi mereka untuk ikut mengadakan kebenarannya sendiri di pentas "kekuasaan" sebagai tawaran kebenaran the other kepada, alias melawan, yang selama ini menjadi penguasa "sah" kebenarankebenaran.

\section{DAFTAR RUJUKAN}

Appadurai, Arjun. 1990. "Disjuncture and Difference in the Global Cultural Economy" Dalam Mike Featherstone (Ed.) Global Culture, Nationalism, Globalizaion, and Modernity. London: SAGE Publications.

Bateson, Gregory. 1979. Mind and Nature. London: Fontana Paperback.

Capra, Fritjof. 1997. Titik Balik Peradaban, Sains, Masyarakat, dan Kebangkitan Kebudayaan (terjemahan). Yogyakarta: Yayasan Bentang Budaya.

Darma Putra, Nyoman. 2004. "Kecenderungan Tema Politik dalam Perkembangan Mutakhir Lagu Pop Bali", Jurnal Kajian Budaya, Volume 1 Nomor 2 Juli 2004.

Fadlillah. 2003a. "Cultural Studies" Mazhab Bali, Sebuah Paradigma Baru Kajian Budaya", Kompas, Minggu, 16 Februari.

. 2003b. "'Cultural Studies" Mazhab Bali, Sebuah Pembicaraan Awal", dalam I Gede Mudana (Peny.), Pemahaman Budaya di Tengah Perubahan, Sebuah Cenderamata untuk Prof. Dr. I Gusti Ngurah Bagus. Denpasar: Program S2 dan S3 Kajian Budaya Universitas Udayana.

Foucault, Michael. 1980. Power/Knowledge (Selected Interviews and Other Writings 1972-1977). Sussex: The Harvester Press. . 1985. Discipline and Punish. Middlesex: Penguin Books.

Hobart, Mark. 2000. After Culture: Anthropology as Radical Metaphysical Critique. Denpasar: Program Studi Magister S2 Kajian Budaya Universitas Udayana.

Hobsbawm, Eric. 1988. "I. Introduction: Inventing Traditions" dalam E. Hobsbawm and $\mathrm{T}$. Ranger (Eds.) The Invention of Tradition. Cambridge, Great Britain: Cambridge University Press.

Kaler, I Gusti Ketut. 1983. Butir-butir Tercecer tentang Adat Bali 2. Denpasar: Bali Agung. 